\title{
Case study: mapping the tsunami-hazard zone in the Pasir Jambak sub-district, in Padang, Indonesia
}

\author{
Leli Honesti ${ }^{1}$ and Meli Muchlian ${ }^{1 *}$ \\ ${ }^{1}$ Department of Civil Engineering, Faculty of Engineering, Padang Institute of Technology, Indonesia
}

\begin{abstract}
A tsunami hazard is an adverse event that causes damage to properties and loss of life. The problem in assessing a tsunami risk zone for a small area is significant, as available tsunami inundation zone data does not give detailed information for tsunami inundation and run-up in every nested grid. Hence, this study aims to establish a tsunami risk map in the Pasir Jambak sub-district, Padang, Indonesia. The map was carried out in every nested grid point of the area and on a large scale $(1: 5,000)$. The TUNAMI N3 program was used for the simulation of the tsunami inundation. A tsunami assessment was made through simulations in nine scenarios of fault parameter data for Sipora block earthquakes. The result of the study provides a tsunami inundation map. Furthermore, this tsunami inundation map can be used for communities, local authorities, government, and others for many studies, and decision-makers can come up with mitigation plans for a small study area.
\end{abstract}

\section{Introduction}

Many countries in this world are located within zones where the tectonic plates are active. Most of these coastal areas are vulnerable to tsunamis. In several parts of the different regions in Indonesia, such as North Sumatra, West Sumatra, south of Java, north coast of Sulawesi, Maluku, and north coast of Papua, the risks for tsunamis are very high [1-9]. The effects of a tsunami in coastal areas in some countries are devastating, where tsunami disaster changes within the hazard zone in response to some parameters, especially reflecting the character of the urban environment $[10,11]$. Tsunami waves mainly affect low-lying coastal areas. However, when tsunami waves become extremely large in height, they savagely attack coastlines, causing devastating property damage and loss of life. When a tsunami occurs, the forces release hydrodynamic pressure, erosion (scouring), buoyancy, as well as the effects of objects and debris carried by the water $[5,7]$.

If an area is very close to the earthquake epicenter, residents may only have a short time to evacuate when a tsunami occurs. Numerical simulations can estimate the arrival time of the tsunami waves on the coast. Therefore, tsunami simulation can be used to estimate tsunami runup, arrival time, and inundation. This information can be used to determine the tsunami hazard level in an area [3,12-15]. Here, numerical models are used to predict physical tsunami characteristics. This is usually a set of mathematical formulas, called a tsunami model, to predict the tsunami waves and their coastal impact. Most computer methods were developed to simulate tsunami inundation. Tsunami prediction methods are the synthesis of earthquakes, wave evolution, and flood inundation models. Several previous tsunami simulations are presently in use, including MOST, TUNAMI, SELFE, Comcot [16-21].

Previous studies related to tsunami disasters have been carried out, but tsunami hazards that provide detailed information about tsunami waves on the coast, tsunami inundation, and run-up are still rare [7]. The problem in assessing the tsunami risk zone for a small area is significant, as available tsunami inundation zone data do not give detailed information for tsunami inundation and run-up in every nested grid [19-22]. Hence, the objective of this study is to establish a detailed tsunami inundation map in a small area. The study area is in Pasir Jambak Sub-district, in Padang, Indonesia.

Padang is the capital city of West Sumatra province, Indonesia. It has an area of $694.96 \mathrm{~km}^{2}$ with the sea as the borders and surrounding hills that are 1,853 meters above the average sea level. The city, located between latitudes $0^{\circ} 44^{\prime} 00^{\prime \prime}-1^{\circ} 08^{\prime} 35^{\prime \prime} \mathrm{S}$ and longitudes $100^{\circ} 05^{\prime} 05^{\prime \prime}$ $100^{\circ} 34^{\prime} 09^{\prime \prime} \mathrm{E}$, is among the most seismically active zones on the western coast of Sumatra. It has experienced earthquakes followed by tsunamis with at least $5 \mathrm{~m}$ of runup heights between $\mathrm{Mw} 8.7$ and 9.0 of earthquake magnitude and is a 200 year-return-period tsunami [4]. Pasir Jambak sub-district is located between latitude $0.8575-0.8608 \mathrm{~S}$ and longitude $100.3283-100.3450 \mathrm{E}$. The study area lies along the Padang coast and faces the Mentawai islands. The coastal areas are low-lying areas. Those zones consist of sandy beaches. The maximum tsunami inundation generally occurs on sandy shores [23].

* Corresponding author: melimuchlian@itp.ac.id 
Those areas have large communities and different types of dwellings, with $12.5 \%$ of the whole of Padang city's population.

Based on the tsunamis that occurred in 1797 and 1833, the tsunami arrival times were around 30 minutes with a $5 \mathrm{~m}$ tsunami height on the coast of West Sumatra. The tsunami wave height along Muaro Padang was also about $5 \mathrm{~m}[1,2]$. In 2006, the tsunami run-up simulations for West Sumatra were made by Jose C. Borrero et al. [21]. The simulation was published by the National Academy of Science in the USA in 2006. For this, they used the MOST (Method of Splitting Tsunami) numerical simulation.

Developing tsunami generation and propagation models is a very challenging task as it involves many facets: for example the formation of different wave types and the impingement of these waves on the coast. There have been several computational issues worthy of consideration. To determine tsunami generation, propagation, inundation, and run-up, most tsunami simulations have been equipped with all the dimensions and parameters. However, the influence of a tsunami height and the arrival time of tsunami wave propagation are different, since a tsunami source depth is not proportional with tsunami height [24,25].

A tsunami disaster can be designed by different simulations and development. Some parameters, such as the various predictions, approximations, domains, and coastal features, topographic and bathymetric features, play important roles in accurate tsunami hazard assessment in a coastal area. Therefore, it is important to include all the major factors for tsunami wave simulation, namely the tsunamigenic earthquake sources, earthquake parameters, tsunami wave propagation, tsunami inundation, and run-up. Many researchers have also modeled tsunami hazard zones based on the maximum inundation extent and depth.

\section{Methodology}

To obtain detailed attributes of tsunami inundation based on tsunami simulations, this study used the simulation results from Sipora Blocks in the Mentawai islands to acquire the water element of tsunami wave inundation at every grid point of the study area site. The TUNAMI N3 program was used for the simulation of the tsunami inundation. The tsunami simulation result is used to establish a tsunami risk zone. To get detailed and informative simulations, it would have to be carried out in nine varying scenarios and three different earthquake depths. The epicenter is located in the west of Sipora island, with magnitudes of Mw 8.0:8.5:9.0 and depths of 10:25:35 km. The tsunami generation source was estimated from the Sipora block seismological fault model. The input datasets in tsunami wave's numerical simulation, consisting of some fault parameters in the Sipora block are recorded in Table 1. The selection of this area is based on the history of 200 years of earthquakes, which took place in 1797 [1,2], [4].

The Google Earth and Map Source software were used in determining the domain areas. The bathymetry and topography datasets are the basic data required for tsunami simulation. To provide topography data, this research used the datasets from the SRTM (Shuttle Radar Topography Mission) of $90 \mathrm{~m} \mathrm{DEMs,} \mathrm{with} 90 \mathrm{~m}$ resolution or three seconds for earth ground surface, while the SRTM grids of topography elevation data were used to derive the topography data. Meanwhile, the GEBCO (General Bathymetric Chart of the Oceans) was used to obtain the bathymetry data files in the areas observed, with 30 arc-second $(1 \mathrm{~km})$ for the data. For this study, the GEBCO and the SRTM datasets were used for both the gridded bathymetry and the topography data. Global Mapper Software was used to process the topography data files and coastline parameters. In the next process, the topographic and bathymetric datasets were interpolated by using the Surfer software. Next, the numerical datasets were graphically shown by using the Transform software so that they could be presented in degree coordinates and UTM (Universal Transverse Mercator) coordinates and saved in (.txt) format.

The method of nested grids is a combination of linear simulation and the nonlinear approach $[12,16]$. In these tsunami simulations, the computational areas of study were divided into four domains, (A, B, C, and Ddomains). A-domain grid is presented in Fig. 1. The nested grids of the research study with these four domains have four different spatial grid sizes. Every domain contains the bathymetric and topographic datasets in different grids.

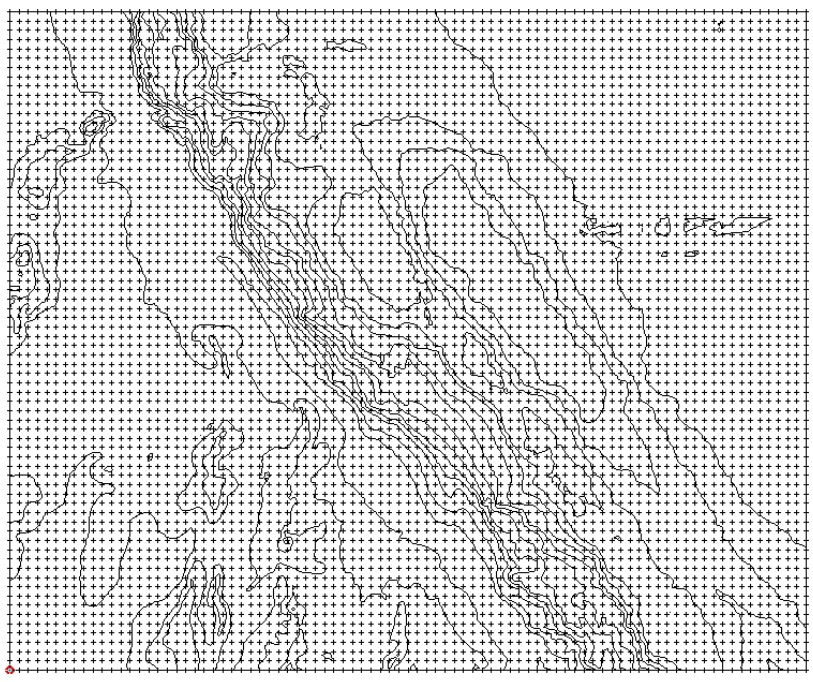

Fig. 1. A domain grid data

The inundation and run-up were simulated for several scenarios. In this study, various parameters of tsunami simulation were presented. There were bathymetry, topography, earthquake magnitude, earthquake source, and fault rupture. The determination of earthquake source parameters was based on historical tsunamis and earthquake-induced tsunamis generated by active faults in the Sumatran megathrust. It is based on tsunami height data, which had occurred in the case study area.

The TUNAMI Number 3 (TUNAMI-N3) Imamura program was used in this study to run the linear and the nonlinear (with four different nested grid sizes) simulations of the tsunami wave inundation within the 
near-field. These need some input datasets to derive the tsunami wave simulation, such as the domain of observation area, the hypocentre and epicenter of earthquakes, the fault parameters, the running time, and the reference point of the tide level. The initial model of tsunami waves took reference from the vertical deformation of the ocean floor. The faults position in the framework of the tsunami wave inundation simulation was based on the reference point from the left-under angle $(0,0)$.

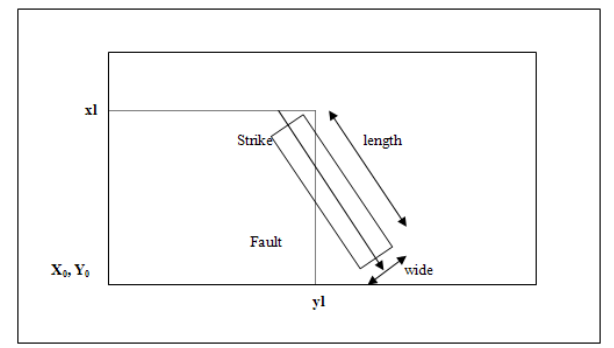

Fig. 2. Fault model in the framework of tsunami wave generation
The variables $\mathrm{x} 1$ and $\mathrm{y} 1$ of the earthquake epicenter were stated in the nested grid boundaries. The faults model in the framework of tsunami wave inundation can be seen in Fig. 2. This simulation investigated the tsunami tide level, tsunami inundation, tsunami propagation, simulations verification, and validation, as well as the tsunami hazard zones. This should be more informative for users, readers, and decision-makers. An inundation map was provided to present the tsunami simulation results in the fields.

\subsection{Tsunami tide level}

A graphic of tsunami tide level description displays the relation between the heights and the tsunami arrival times in four nested grid points of the areas observed. The graphic datasets of the seawater level were analyzed based on a tide level reference point within a long period. A long time was needed to simulate an initial tsunami wave to reach the tide level reference point in the observed areas. In addition, the maximum tsunami heights in the areas observed can be analyzed from the graphic.

Table 1. Fault parameter data for Sipora block earthquake

\begin{tabular}{|c|c|c|c|c|c|c|c|c|c|c|}
\hline Scenario & Xgrid & Ygrid & M & HH & D & L & W & TH & DL & RD \\
\hline Scenario 1 & 126 & 107 & 8.0 & 10 & 3.23 & 111 & 55 & 130 & 100 & 80 \\
\hline Scenario 2 & 126 & 107 & 8.5 & 10 & 9.09 & 313 & 156 & 130 & 100 & 80 \\
\hline Scenario 3 & 126 & 107 & 9.0 & 10 & 10.20 & 352.09 & 176.04 & 130 & 100 & 80 \\
\hline Scenario 4 & 126 & 107 & 8.0 & 25 & 3.23 & 111 & 55 & 130 & 100 & 80 \\
\hline Scenario 5 & 126 & 107 & 8.5 & 25 & 9.09 & 313 & 156 & 130 & 100 & 80 \\
\hline Scenario 6 & 126 & 107 & 9.0 & 25 & 10.20 & 352.09 & 176.04 & 130 & 100 & 80 \\
\hline Scenario 7 & 126 & 107 & 8.0 & 35 & 3.225 & 111 & 55 & 130 & 100 & 80 \\
\hline Scenario 8 & 126 & 107 & 8.5 & 35 & 9.09 & 313 & 156 & 130 & 100 & 80 \\
\hline Scenario 9 & 126 & 107 & 9.0 & 35 & 10.20 & 352.09 & 176.04 & 130 & 100 & 80 \\
\hline
\end{tabular}

\subsection{Tsunami inundation}

The tsunami inundation was derived using the maximum tsunami run-up simulation data. Image processing software was used to show the numerical data in the graphic form before and after the run-up in the areas observed. By comparing the two graphics in every nested grid, the inundation levels for each nested grid were obtained. Then, all the data were interpreted in a digital inundation map by using the ArcView GIS 3.3 software, in which the size of the grid has been adjusted.

\subsection{Tsunami propagation}

The tsunami height datasets output program in every nested grid was 10,800 seconds, with every scene file of 40 seconds produced in 270 pieces of data. The running data was converted into an image format. Next, those files were compiled in one folder to produce an animation video. This visualization has made it easy to develop a pattern of tsunami wave propagation.

\subsection{Verification of simulations}

Every tide level model was verified by historical tsunami databases. In addition, if a simulation result was not based on the verification and validation of computer simulation of the historical databases, it could be simulated again by changing the earthquake parameters and/or the tide level reference point and/or the domain quality measurement.

\subsection{Tsunami hazard zone}

The result of tsunami simulation is the height of tsunami run-up and inundation on land. The simulation result is presented by zoning the area in the tsunami hazard zone map.

\section{Results and discussion}

Tsunami scenarios were obtained by conducting various tsunami simulations. The simulation result of a $5 \mathrm{~m}$ runup height was used to provide the inundation data in every nested grid point. Based on the maximum heights and 
travel time, a tsunami generated from a potential tsunami source along the megathrust to the coast of the case study, it can be seen that bigger earthquake magnitudes generate a tsunami wave that is higher and has a shorter travel time. From the result of nine simulations of tsunami waves, it can be concluded that the highest results for tsunami obtained was $10 \mathrm{~km}$ depth with a magnitude of (Mw) 9.0. Tsunami wave heights, here, were taken from the maximum tsunami height.

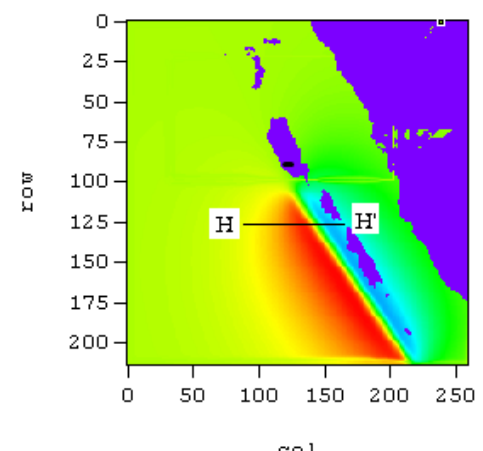

(a)

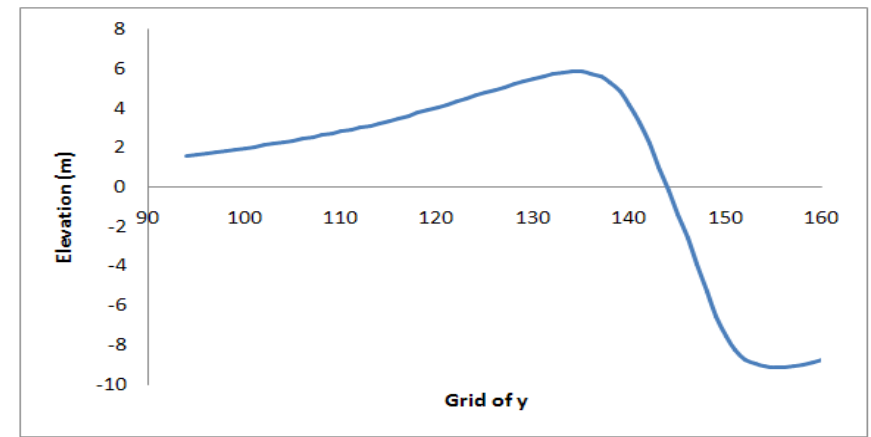

(b)

Fig. 3. Tsunami height of beginning (a) and H-H' Crossection Sipora block (b)

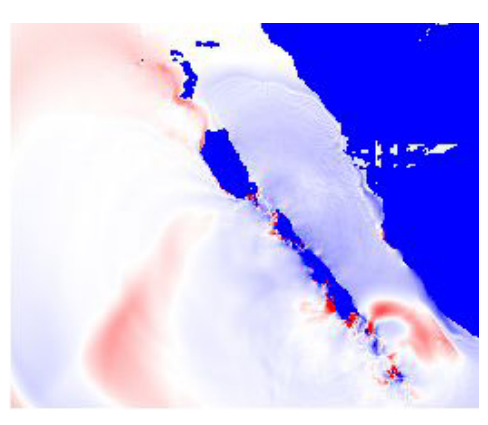

(a)

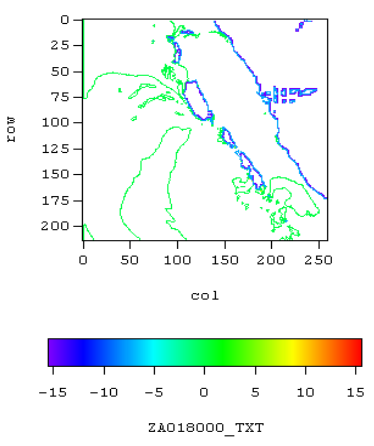

(b)

Fig. 4. Model (a) and contour (b) of tsunami inundation 34 minutes after an earthquake in A-domain

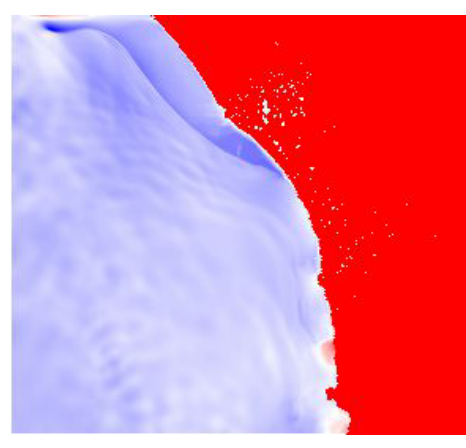

(a)

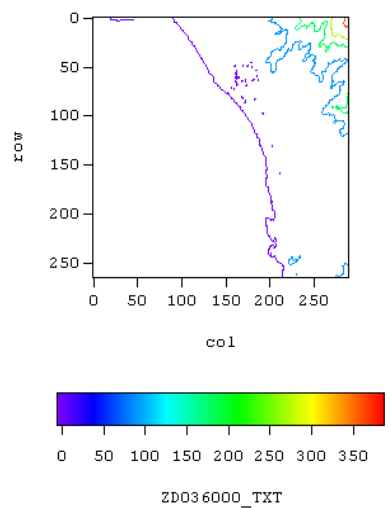

(b)

Fig. 5. Model (a) and contour (b) of tsunami inundation 90 minutes after an earthquake in D-domain in Sipora block

The initial condition of a tsunami wave is shown in Fig. 3(a). Thus, the H-H' cross-section is the fluctuation of tsunami height at the tsunami generation point. The positive value is $(+3.21 \mathrm{~m})$, and the negative value is $(-$ $4.78 \mathrm{~m}$ ), given the initial maximum tsunami height is $7.99 \mathrm{~m}$. Apart from that, the waveform can be seen in Fig. 3(b).
The tsunami propagation can be seen in Fig. 4. Here, in 34 minutes, the seawater levels decreased in all observed area points. Water level fluctuation is shown in blue-colored contour in the event when the waves decrease and red-colored contour when the waves increase. Fig. 5 shows that the tsunami hits the observation areas in 90 minutes. 
Table 2. Tide level position

\begin{tabular}{|c|c|c|}
\hline Scenario & \multicolumn{2}{|c|}{ Pasir Jambak sub-district } \\
\hline \multirow{2}{*}{9} & arrival time & $\begin{array}{c}\text { tsunami wave height } \\
\left(\mathrm{h}_{\max }\right)\end{array}$ \\
\cline { 2 - 3 } & 36 minute & $5.70 \mathrm{~m}$ \\
\hline
\end{tabular}

Table 2 shows the results of tsunami arrival time and the tsunami wave height in the Pasir Jambak sub-district. Tide level fluctuations were caused by a tsunami sourced from the Sipora block in the Mentawai islands. The initial tsunami wave is indicated by a decrease in the tide level approximately 35 minutes after the earthquake. Before reaching the observation areas, tsunami waves are first hampered by the west of the Mentawai islands, directly facing the tsunami source.

Fig. 6 is the graphic showing the tide level elevation of the tsunami in the observation areas. The height of the tsunami wave is $5.70 \mathrm{~m}$ in the Pasir Jambak sub-district.
This is because $80 \%$ of the initial tsunami wave has been hampered by the Mentawai islands, while some others diffracted through the gap between the islands. The reduction of tsunami energy is generally beneficial for the observation area, but it will still be so dangerous for the area that is directly stricken by the waves.

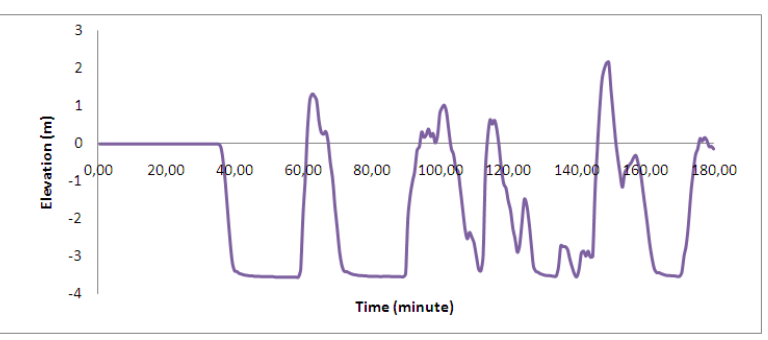

Fig. 6. Tide level from Sipora block source

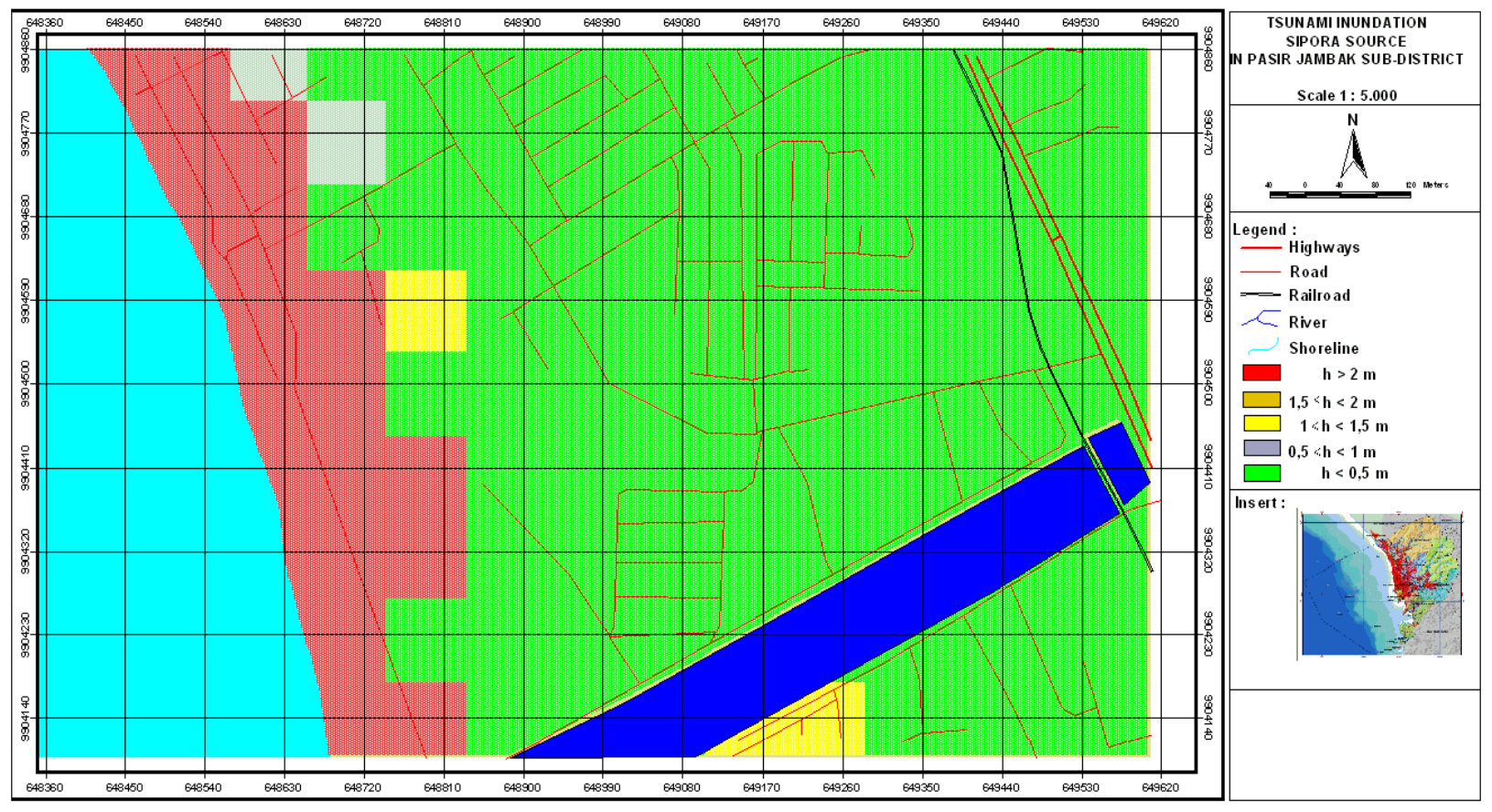

Fig. 7. Tsunami inundation map from Sipora block source in Pasir Jambak sub-district

Along the coastal area of the Pasir Jambak subdistrict, the average water heights are more than $2 \mathrm{~m}$, but the tsunami inundation is only $200 \mathrm{~m}$ from the coastline. Tsunami inundation in the Pasir Jambak sub-district in Fig 7 describes the inundation map with a red color code distributed near shore. The most vulnerable fields with red color are concentrated in the seashore. There are approximately 18 nested grids or around $154,800 \mathrm{~m}^{2}$ of an area that can be considered the most vulnerable. A red code in the sub-district is more deeply inundated. The yellow and grey coded areas can be seen in only three nested grids or around a comparable area of 24,300 $\mathrm{m}^{2}$, and in two nested grids or approximately $16,200 \mathrm{~m}^{2}$ for the orange color code. More than three-quarters of the area of study is the green coded zone.

The tsunami inundation map was made on a large scale $(1: 5,000)$, and the map has detailed information for tsunami inundation and run-up in every grid. It can also be used to provide an informative tsunami hazard zone so that it plays an important role for users and decisionmakers in mitigation.

\section{Conclusion}

The study of the tsunami hazard zone is based on a multi-scenario approach of tsunami parameters, which integrates simulated tsunami scenarios. The simulations were performed in three scenarios of magnitudes $(8 ; 8.5$ and 9.0) and three scenarios of earthquake depths (10; 25 and $35 \mathrm{~km}$ ). Tsunami run-up and inundation simulations are shown in large-scale maps $(1: 5,000)$. The simulations have been carried out based on detailed data, attributes, and parameters, model development in the field studies. The development results of tsunami simulations were elaborated to assess the tsunami hazard zone in every nested grid point.

Tsunamis beneath the Mentawai islands of West Sumatra, Indonesia, were verified with historical 
tsunamis in the coastal area of Padang, based on the earthquakes and tsunamis in 1797 and 1833 so that there is a variety in the earthquake parameter and tsunami simulations with tsunami run-up are approximately 5 meters. The tsunami risk zone map includes more detailed information for tsunami inundation and run-up in each grid, a small scale, and a small area. Furthermore, this map can be used for the communities, local authorities, government as well as others for many studies.

\section{References}

1 J. du Puy, Tijdsch Neerland's Indie, 7 (1845)

2 J. du Puy, Tijdsch Neerland's Indie, 9 (1847)

3 D. Mardiatno, Tsunami Assessment Using Scenario-Based Approach, Geomorphological Analysis, and Geographic Information System, A Case Study in South Coastal Areas of Java IslandIndonesia, University of Innsbruck, (2008)

4 D. H. Natawidjaja, K. Sieh, M. Chlieh, J. Galetzka, B. W. Suwargadi, H. Cheng, R. L. Edwards, J. P. Avouac, and S. N. Ward, J. Geophys. Res. Solid Earth, 111 (2006)

5 K. Satake, Y. Nishimura, P. S. Putra, A. R. Gusman, H. Sunendar, Y. Fujii, Y. Tanioka, H. Latief, and E. Yulianto, Pure Appl. Geophys, 170 (2013)

6 K. Satake, Geosci. Lett. 1 (2014)

7 B. A. D. Van Veen, D. Vatvani, and F. Zijl, Cont. Shelf Res, 79 (2014)

8 Y. Fujii and K. Satake, Geophys. Res. Lett, 33 (2006)

9 Y. Tanioka, H. Latief, H. Sunendar, A. R. Gusman, and S. Koshimura, J. Disaster Res, 7 (2012)

10 Papathoma and D. Dominey-Howes, Nat. Hazards Earth Syst. Sci, 3 (2003)
11 M. Papathoma, D. Dominey-Howes, Y. Zong, and D. Smith, Nat. Hazards Earth Syst. Sci, 3 (2003)

12 F. Imamura, A. C. Yalçiner, and G. Ozyurt, Tsunami Model. Man, (2006)

13 E. Jelinek, R. Eckert, S., Zeug, G., and Krausmann, Tsunami Vulnerability and Risk Analysis Applied to the City of Alexandria, Egypt, Italy (2009)

14 E. L. Lekkas, E. Andreadakis, I. Kostaki, and E. Kapourani, Bull. Seismol. Soc. Am, 103 (2013)

15 UNDP, Developing a Disaster Risk Profile for Maldives (2006)

16 IOC and C. Goto, IOC Man. Guid, 35 (1997)

17 V. V Titov and F. I. Gonzalez, NOAA Tech. Memo. ERL PMEL-112 (1997)

18 Y. J. Zhang, A. Baptista, and O. Health, in Coast. Zone 07, Portland, Oregon, 1-6 (2007)

19 R. L. Priest, G. R., Witter, R. C., Zhang, Y. J., Wang, K., Goldfinger, C., Stimely, L. L., English, J. T., Pickner, S. G., Hughes, K. L.B., Wille, T. E., and Smith, Tsunami Inundation Scenarious For Oregon (2013)

20 O. Q. Gutiérrez, I. Aniel-Quiroga, M. Gonzalez, and L. Guillou, Coast. Eng. Proc, 1 (2014)

21 J. C. Borrero, K. Sieh, M. Chlieh, and C. E. Synolakis, Proc. Natl. Acad. Sci. U. S. A, 103 (2006)

22 A. P. Patel, V. M., Dholakia, M. B., and Singh, Int. J. Eng. Sci. Innov. Technol. IJESIT 2, 130 (2013)

23 L. Honesti, M. Z. Abd Majid, M. Muchlian, and N. Djali, J. Teknol, 69 (2014)

24 Y. Yudhicara, Indones. J. Geosci, (2008)

25 L. Honesti, M. Z. A. Majid, N. Djali, and M. Muchlian, J. Teknol, 72 (2015) 